\title{
BMJ Open Association between Carbohydrate Quality Index and general and abdominal obesity in women: a cross- sectional study from Ghana
}

\author{
Sufyan Bakuri Suara, ${ }^{1}$ Fereydoun Siassi, ${ }^{2}$ Mahama Saaka, ${ }^{3}$ \\ Abbas Rahimi Foroshani, ${ }^{4}$ Gity Sotoudeh (1) ${ }^{5}$
}

To cite: Suara SB, Siassi F, Saaka M, et al. Association between Carbohydrate Quality Index and general and abdominal obesity in women: a cross-sectional study from Ghana. BMJ Open 2019;9:e033038. doi:10.1136/ bmjopen-2019-033038

- Prepublication history and paper are available online. To view these files, please visit the journal online (http://dx.doi. org/10.1136/bmjopen-2019033038).

Received 17 July 2019 Revised 16 November 2019 Accepted 18 November 2019 additional material for this

\begin{abstract}
Objectives The relationships between carbohydrate intake and risk of obesity have been widely investigated. However, there are limited data on the associations between their relative proportions and quality contained in the same diet on risk of obesity, especially in low-income and middle-income countries. The aim of this study was to assess the relationship between an overall Carbohydrate Quality Index (CQI) and general and abdominal obesity in women.
\end{abstract}

Setting and participants In this cross-sectional study, data from 277 women in Ghana were analysed. Dietary information was obtained from 2-day 24 hours dietary recalls. CQI was calculated from the four indices dietary fibre, Glycaemic Index, whole grains/total grains ratio and solid carbohydrates/total carbohydrates ratio.

Outcome measures Body mass index, waist circumference (WC), waist-to-height ratio (WHtR) and Conicity Index were measured.

Results After adjusting for covariates, the chance for general obesity (OR $0.25,95 \% \mathrm{Cl} 0.10$ to 0.65 ) and abdominal obesity measured by WC (OR $0.22,95 \% \mathrm{Cl} 0.08$ to 0.58 ) were significantly lower in the topmost quintile of $\mathrm{CQI}$ in comparison with the lowest quintile. In addition, the OR for higher WHtR (OR $0.27,95 \% \mathrm{Cl} 0.11$ to 0.69 ) was significantly lower among participants in the fifth quintile of CQI compared with those in the first quintile.

Conclusions The present study demonstrates that there is an inverse association between dietary $\mathrm{CQI}$ and both general and abdominal obesity. These findings suggest that CQI may be used for the improvement of dietary intake to prevent obesity.

Check for updates

(C) Author(s) (or their employer(s)) 2019. Re-use permitted under CC BY-NC. No commercial re-use. See rights and permissions. Published by BMJ.

For numbered affiliations see end of article.

Correspondence to Dr Gity Sotoudeh; gsotodeh@tums.ac.ir

\section{INTRODUCTION}

The incidence of obesity and overweight is increasing globally. If the present trends remain unchecked, 2.16billion and 1.12 billion adults may become overweight and obese, respectively, by 2030. ${ }^{12}$ Previously, a systematic review showed that about $43 \%$ of the adult population in Ghana suffer from either obesity or overweight. ${ }^{3}$

Positive associations have been suggested between total carbohydrate consumption

\section{Strengths and limitations of this study}

- This study was the first to comprehensively investigate Carbohydrate Quality Index (CQI) and its relationship with general and abdominal obesity in Ghana.

- The sample size was quite small.

- The effects of eating behaviour, menopausal status, genetic variations and residual confounding were not addressed.

- This was a cross-sectional study; the findings do not establish causality between CQI and obesity.

- Self-reported dietary information may suffer from random and systematic errors, however, necessary precautions were taken during the data collection and analysis to avoid possible errors.

and chance of obesity. However, the evidence is inconsistent. ${ }^{4}$ A systematic review of observational studies concluded that a highcarbohydrate diet is not related to higher odds of obesity. ${ }^{4}$ Furthermore, two crosssectional studies from Africa reported mixed results. ${ }^{5}$ However, these studies did not adjust for energy intake. In addition, this discrepancy may suggest that the association between obesity and carbohydrate nutrition might be better explained based on a broader evaluation of its quality.

The results from cross-sectional studies on either Glycaemic Index (GI), glycaemic load (GL), or both have found null, ${ }^{7}$ positive $^{89}$ or inverse ${ }^{10}$ relationships with obesity. These studies have controlled for confounding variables such as age, sex, region, education, total energy intake, smoking status, marital status, physical activity, breakfast skipping and home ownership. Information on the relationship between dietary GI, GL, total fibre and consumption of liquid carbohydrates in relation to obesity in Ghana is lacking. However, one cross-sectional study showed a positive 
association between the intake of refined carbohydrates and abdominal obesity. ${ }^{11}$ In contrast, no significant association was found between consumption of polished cereals and grains and central obesity in Ghanaian adults. ${ }^{12}$

The mentioned studies are limited in their scope, because a single component cannot entirely represent the overall quality of carbohydrate nutrition. Therefore, broader criteria that incorporate several of these single components into a composite index could better represent the overall quality of dietary carbohydrate intake. A previous study ${ }^{13}$ defined Carbohydrate Quality Index (CQI) by taking into account dietary fibre intake, GI, whole grains-to-total grains ratio and solid carbohydrate to total carbohydrates. The inverse association between CQI and obesity/overweight has been shown in one prospective study ${ }^{14}$ and in a cross-sectional study in adults. ${ }^{15}$ However, both of these studies assessed only general obesity based on body mass index (BMI) criteria. Abdominal obesity identification and its related dietary carbohydrate quality ought to be a priority.

As mentioned before, the prevalence of obesity is high in Ghana. ${ }^{3}$ On the other hand, dietary carbohydrates provide almost $90 \%$ of the energy intake among the adult population in the country, ${ }^{16}$ which implies that compare to fat and protein, the intake of carbohydrate may have a more prominent role in the health maintenance of the population. Therefore, identifying modifiable lifestyle risk factors such as CQI in a broader fashion might be more useful in obesity prevention and management. Hence, the purpose of this study was to determine the association between dietary CQI and chance of general and abdominal obesity among women in Tamale Metropolis, Ghana.

\section{METHODS AND SUBJECTS}

\section{Study design and population}

This cross-sectional study was performed in adult women within Tamale Metropolis. All study data were collected over a 2-month (August/September 2018) period. The main objective of the study was to ascertain associations between CQI and general and abdominal obesity. The study included women within the ages of 18-59 years living in the study region for at least a year. Women with a previous history of any major illness such as myocardial infarction, renal disease or other major illnesses (diabetes, human immune deficiency virus, renal disease, cardiovascular diseases (CVD), malaria) were excluded from the study. Additionally, those who were experiencing persistent severe nausea with vomiting, pregnant and lactating mothers, and women on any special diet or diet therapy were also excluded from the study.

In order to calculate the required sample size, a correlation coefficient of 0.2 between CQI and anthropometric variables was hypothesised, and a confidence level of $95 \%$ and a power of test of $80 \%$ were considered. The sample size was initially calculated as 195 based on the formula for cross-sectional study designs proposed by Rosner. ${ }^{17}$ To increase the power of the statistical results and to provide room for the non-response rate, 195 was multiplied by 1.5 , and the total number of subjects of 295 was ultimately chosen. All study participants were randomly selected and consented to participate in the study.

\section{Patient and public involvement}

This study included healthy women. Although they were not involved in the study design process, their recruitment and participation were based on their own will without any coercion. Study findings will be made public through publications and in seminars with health authorities within the region, which may help to inform nutrition policy formulation for the benefits of reducing the risk and prevalence of obesity in the country.

\section{Dietary assessment and CQI calculation}

All dietary were collected using repeated but nonconsecutive 2-day 24 hours dietary recalls. Real food items, food models and kitchen weighing equipment were used to guide participants in estimating portion sizes of food items consumed. A trained caterer (home science practitioner) conducted all interviews face to face using a three-stage multiple pass approach with quick listing, detail description and reviewing, and prompting for possibly forgotten food items. GI values were obtained from international tables. ${ }^{18}$ Glucose was used as the reference (GI for glucose $=100$ ). The mean of the GI values was assigned if more than one eligible GI value was available for a specific food item. GI values assessed using healthy subjects were given preference. The GI for millet porridge was obtained from the University of Sydney GI database. ${ }^{19}$ The GI of sorghum, ${ }^{20}$ tuo-zaafi and banku ${ }^{21}$ were obtained from the published articles. The carbohydrate content of foods consumed was determined using standard portion sizes from the United States Department of Agriculture food composition databases. ${ }^{22}$ Mean daily values of dietary energy, fibre and total carbohydrates over the 2-day period were used in the analysis. Subjects who had average dietary energy intake levels outside the predefined minimum limit $(<500 \mathrm{kcal} /$ day $)$ and an upper limit $(>3500 \mathrm{kcal} / \text { day })^{23}$ were excluded. After these exclusions, 277 complete datasets per person were used in the analysis to establish the relationship between CQI and obesity/overweight. The weighted daily dietary GIs were calculated using the suggested formula: Weighted GI $=\sum$ (carbohydrate content of food item $(\mathrm{CHOi}) \times \mathrm{GIi} /$ daily total food carbohydrate content; where CHOi is each food's carbohydrate content, GIi is each food's GI and GIi is the GI value for the food. ${ }^{15}$ The GL value was calculated for each participant by multiplying the carbohydrate content in grams obtained from the portion of food consumed by the corresponding GI of that food divided by 100 . The individual GL values for each food item were summed to derive the total daily GL consumed. ${ }^{24}$ By definition, liquid carbohydrates were calculated as the sum of the carbohydrates from all sugar-sweetened beverages and fruit juices consumed, whereas solid carbohydrates 
were considered to be the carbohydrate content of the rest of the carbohydrate-based food items. ${ }^{14}$

CQI was computed based on the energy-adjusted amount of total carbohydrate intake values calculated using the residual method. ${ }^{25} \mathrm{CQI}$ was defined by summing up the following four criteria: ratio of solid carbohydrates to total carbohydrates, dietary fibre intake (g/day), GI and the ratio of whole grains to total grains (whole grains, refined grains and their products). For each of these four criteria, subjects were categorised into quintiles and received a value (ranging from 1 to 5 ) according to each quintile. However, the scoring of GI was reversed; thus, those in the fifth quintile received one point and those in the first quintile received five points. Finally, an overall CQI was computed by adding together all values of the four criteria (ranging from 4 to 20). It was also ranked into quintiles. ${ }^{13}$

\section{Anthropometric assessment}

Weight was measured to the nearest $100 \mathrm{~g}$ using a Seca weighing scale (Seca and Co. KG; 22089 Hamburg, Germany; Model: 874 1321009; designed in Germany; made in China). The UNICEF height board was used for height measurements, which were recorded to the nearest $0.1 \mathrm{~cm}$. BMI was calculated as weight (in kilograms) divided by height (in metres squared). Normal weight was defined as BMI $\leq 24.9 \mathrm{~kg} / \mathrm{m}^{2}$, and the presence of overweight and obesity as BMI $=25-29.99 \mathrm{~kg} / \mathrm{m}^{2}$ and $\geq 30 \mathrm{~kg} / \mathrm{m}^{2}$, respectively. ${ }^{26}$ Waist circumference (WC) was measured according to the guiding protocol of WHO, at the midpoint between the lower border of the rib cage and the iliac crest, using a non-stretchable fibre glass measuring tape $\mathrm{e}^{27}$ and classified according to the International Diabetes Federation criteria. ${ }^{28}$ WC was recorded to the nearest $0.1 \mathrm{~cm}$. Participants were dichotomised based on WC value ((normal: $\mathrm{WC}<80 \mathrm{~cm}$ and abdominal obesity: $\mathrm{WC} \geq 80 \mathrm{~cm})$ ). The Conicity Index $(\mathrm{CoI})$ was calculated according to the equation defined by Valdez: CoI=WC $\quad(\mathrm{m}) /\left[0.109 \times \sqrt{[}(\right.$ weight $\quad(\mathrm{kg}) /$ height $\quad(\mathrm{m})] .{ }^{29}$ Participants were classified into two groups (normal: CoI $<1.18$ and abdominal obesity: CoI $\geq 1.18){ }^{30}$ The waist-toheight ratio (WHtR) was defined as the WC divided by the measured height. WHtR $\geq 0.5$ was adopted for the presence of overweight and abdominal obesity for the purpose of uniformity regarding age differences. ${ }^{31}$

\section{Assessment of demographic and lifestyle factors}

Face-to-face interviews were conducted using a structured questionnaire to collect information about demographic and lifestyle factors such as age, educational status, marital status, occupation, household size, household assets, parity and physical activity (online supplementary file). For the purposes of this study, a composite score was estimated for each respondent as a reflection of the value of household assets owned. Physical activity levels of the participants were measured using the International Physical Activity Questionnaire short form. ${ }^{32}$ Specifically, questions asked the time and number of days within the previous week each person spent on walking and on doing moderate-intensity and vigorous-intensity activities. Total physical activity in metabolic equivalent (MET) was determined by adding the total walking, total moderate and total vigorous activities in MET-minutes/week score units.

\section{Statistical analysis}

To ensure the compliance of data suitability with the chosen analytical techniques, the Kolmogorov-Smirnov test was used to evaluate the normality of the data. Physical activity was found to be positively skewed, so it was natural log transformed before it was used in the regression models.

Energy-adjusted dietary CQI was used to classify participants into quintiles. The general characteristics of participants across CQI quintiles were expressed as means \pm SDs for all continuous variables and percentages and simple counts for those that were categorical. To assess the differences across CQI quintiles, analysis of variance (ANOVA) was used for continuous variables and a chi-square test was used for categorical variables. The means of BMI, WC, $\mathrm{WHtR}$, and CoI across the quintiles of CQI were compared using ANOVA and analysis of covariance. Binary logistic regression was also used to determine ORs and $95 \%$ CIs for the presence of general and abdominal obesity across CQI quintiles in unadjusted and multivariable adjusted models. The possible effects of all variables that showed a significant relationship with CQI or the tendency to influence the chances of obesity or overweight were adjusted. In this context, age, energy intake, respondent education, husband's education, physical activity and ethnicity were entered into the adjusted regression models. All statistical analyses were done using IBM Statistical Package for Social Sciences (V.24; SPSS Inc.), and $\mathrm{p}<0.05$ was considered statistically significant.

\section{RESULTS}

The general characteristics of the women according to the quintiles $(Q)$ of $C Q I$ are provided in table 1 . The prevalence of overweight, general obesity determined by BMI and abdominal obesity using WC was $9.4 \%, 22.7 \%$ and $32.5 \%$, respectively. The prevalence of high WHtR and high CoI was $39.4 \%$ and $45.5 \%$, respectively. The results also revealed that in moving from the lowest to the highest CQI quintiles, participants tended to be older (for trend, $\mathrm{p}=0.04$ ). Dagomba women had higher $\mathrm{CQI}$ values compared with the minority $(\mathrm{p}=0.04)$. Higher consumption rates of total fibre (for trend, $\mathrm{p}<0.001$ ), solid carbohydrate $(\mathrm{CHO}) /$ total $\mathrm{CHO}$ ratio (for trend, $\mathrm{p}<0.001$ ), and whole grain-to-total grain ratio (for trend, $\mathrm{p}<0.001$ ) were directly associated with higher values of dietary CQI. In contrast, CQI was inversely associated with weighted daily dietary GI (for trend, $\mathrm{p}=0.004$ ). However, higher values of CQI were significantly associated with a higher intake of total energy (for trend, $\mathrm{p}<0.001$ ) and total carbohydrates 
Table 1 Characteristic of study participants according to quintiles (q) of Carbohydrate Quality Index (CQI)

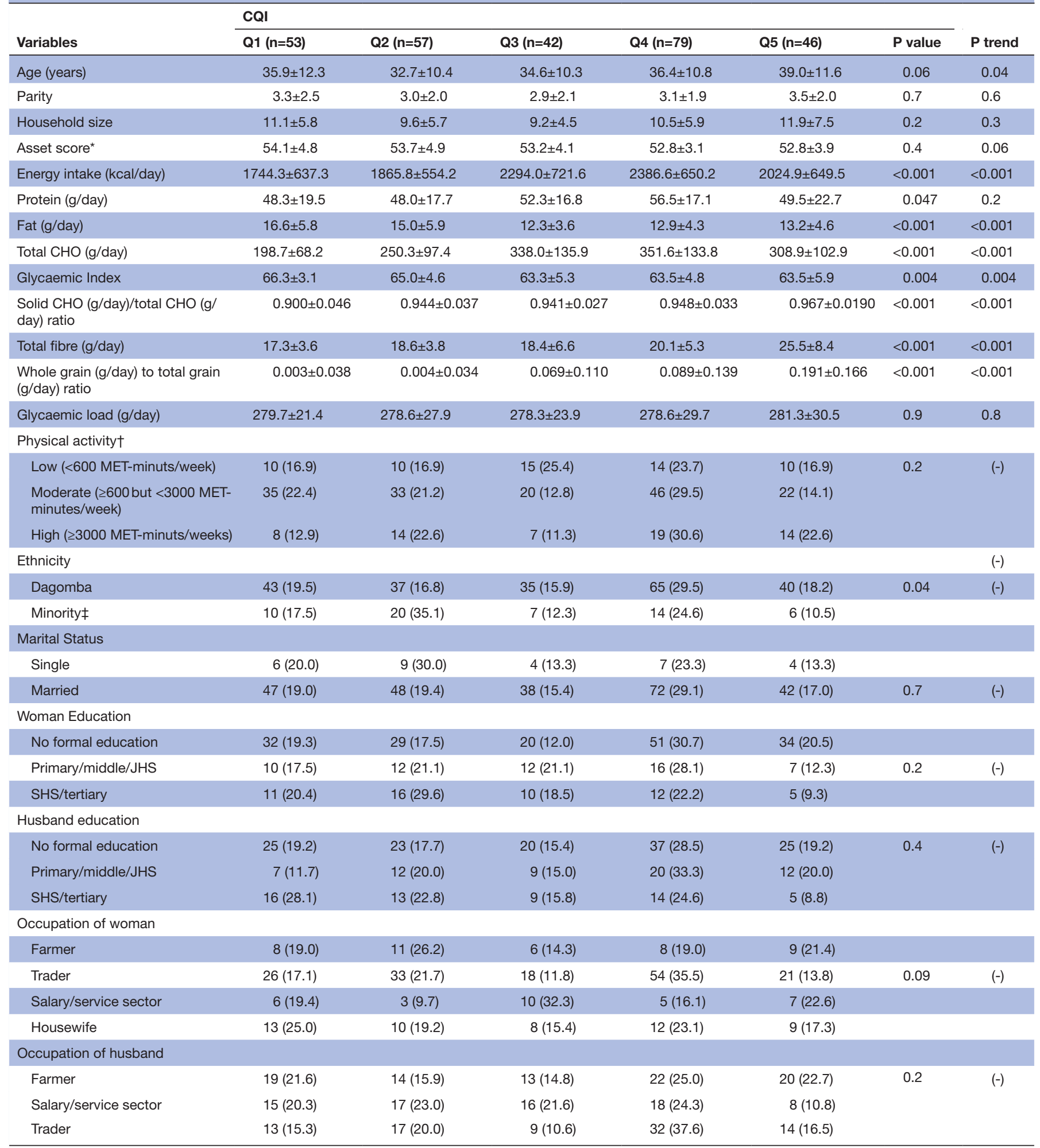

Data are presented as mean \pm SD and number (\%).

${ }^{*}$ An ad hoc index of household asset score was computed from basically number of assets possessed from a list of items provided. A score of 1 point was given for an item owned. As for the main source of cooking energy, drinking water and toilet facility, 1 point was given for unimproved source and two points awarded for improved sources. The total score range was from 37 to 74 with higher scores suggesting enhanced economic strength.

†Low ( $<600$ MET-minuts/week); moderate ( $\geq 600$ but $<3000$ MET-minutes/week); high ( $\geq 3000$ MET-minuts/weeks), p value; obtained by the use of ANOVA or the $\chi 2$ test. P $<0.05$ was considered as statistically significant, $p$ trend; Test of trend was conducted using ANOVA with contrast function.

‡Gonja, gurusi, zambarama, Moshi.

(-), not calculated; ANOVA, analysis of variance; CHO, carbohydrates; JHS, junior high school; SHS, senior high school. 
Table 2 Anthropometric measures according to quintiles (q) of Carbohydrate Quality Index (CQI)

\begin{tabular}{|c|c|c|c|c|c|c|c|}
\hline \multirow[b]{2}{*}{ Variables } & \multicolumn{6}{|l|}{ CQI } & \multirow[b]{2}{*}{ P2 trend } \\
\hline & Q1 (n=53) & Q2 (n=57) & Q3 (n=42) & Q4 (n=79) & Q5 (n=46) & P1 trend & \\
\hline BMI $\left(\mathrm{kg} / \mathrm{m}^{2}\right)$ & $25.6 \pm 5.2$ & $23.9 \pm 4.2$ & $25.1 \pm 5.2$ & $22.0 \pm 4.0$ & $22.1 \pm 3.8$ & $<0.001$ & $<0.001$ \\
\hline WHtR & $0.51 \pm 0.07$ & $0.48 \pm 0.06$ & $0.51 \pm 0.08$ & $0.47 \pm 0.06$ & $0.47 \pm 0.06$ & 0.001 & $<0.001$ \\
\hline Col & $1.17 \pm 0.07$ & $1.15 \pm 0.08$ & $1.18 \pm 0.10$ & $1.16 \pm 0.07$ & $1.16 \pm 0.07$ & 0.9 & 0.5 \\
\hline
\end{tabular}

Data are presented as mean \pm SD; $p$ trend1; unadjusted, significance level of test for trend relationship using ANOVA with contrast function; $\mathrm{p}$ trend2; Significance level of test for trend association in linear regression model with adjustment for age, energy intake (kcal/day), both of respondent and husband's education, physical activity and ethnicity. To analyse these linear trends, the median value of CQI was imputed for each quintile and the new variable was treated as a continuous variable in linear regression model. $\mathrm{P}<0.05$ was considered statistically significant.

ANOVA, analysis of variance; BMI, body mass index; Col, Conicity Index; WC, waist circumference; WHtR, waist-to-height ratio.

(for trend, $\mathrm{p}<0.001$ ). There was no significant association between dietary GL and CQI (for trend, $\mathrm{p}=0.8$ ).

The anthropometric measures according to $Q$ of $\mathrm{CQI}$ are presented in table 2. According to the results, moving from Q1 to Q5 was significantly associated with lower values in $\mathrm{BMI}, \mathrm{WC}$ and $\mathrm{WHtR}$ (for trend, $\mathrm{p}<0.001$ ). There was no significant association between CQI and CoI (for trend, $\mathrm{p}=0.5$ ). These associations remained unchanged even after adjusting for age, energy intake, woman's education and her husband's education, physical activity and ethnicity.

Unadjusted and adjusted ORs and 95\% CIs for obesity and overweight across $\mathrm{Q}$ of CQI are provided in table 3. According to the results, moving from Q1 to Q5 was significantly associated with a lower chance of general obesity (OR $0.23,95 \%$ CI 0.10 to 0.56 ; for trend, $\mathrm{p}<0.001$ ), abdominal obesity using $\mathrm{WC}$ as a proxy (OR $0.22,95 \% \mathrm{CI}$ 0.09 to 0.54 ; for trend, $\mathrm{p}<0.001$ ) and higher WHtR (OR $0.26,95 \%$ CI 0.11 to 0.60 ; for trend, $\mathrm{p}<0.001$ ). There was no significant association between CQI and CoI (OR 0.85, 95\% CI 0.38 to 1.89; for trend, $\mathrm{p}=0.9$ ) (model 1 ). These relationships were found to remain unchanged even after adjustment for age, energy intake, both respondent and husband's education, physical activity and ethnicity (model 2).

Furthermore, the results revealed a higher OR for general obesity in Q3 than in Q2. Also, the OR in Q5 was higher than the OR in Q4.

\section{DISCUSSION}

The present study examined the relationship between dietary CQI and odds of general and abdominal obesity in women. The findings suggest that after adjustment for age, energy intake, both respondent and husband's education, physical activity and ethnicity, the consumption of diets with high CQI levels may be associated with a lower chance for both general and abdominal obesity.

Previously, a study showed that Ghanaian women received $86 \%$ of their energy intake from carbohydrates, especially refined grain products, ${ }^{16}$ which are mainly high GI. ${ }^{21}$ In most sub-Saharan African populations, the increased consumption of added sugars and diets low in fibre have been found, concurrent with increasing trends of obesity. ${ }^{33}$ Data on the relationships between dietary GI, GL, total fibre and consumption of liquid carbohydrates and obesity in Africa are scarce..$^{5611}$ In a cross-sectional study in Egypt, the mean total fibre intake was significantly higher in non-obese individuals than in those who were overweight/obese. ${ }^{6}$ Basu $e t a l^{34}$ analysed data from 75 countries including some in Africa and found that consumption of sugar-sweetened beverages was on the rise, which showed a positive association with a high chance of obesity. In another cross-sectional study, the intake of refined food items high in carbohydrate content, such as starchy roots and tubers, showed a positive association with a higher chance of abdominal obesity in Ghanaian University students. ${ }^{11}$

The inverse association between dietary CQI and general obesity in the present study is in line with the results of a large cross-sectional study in South Korea ${ }^{15}$ and a cohort study from Spain in university graduates. ${ }^{14}$ However, unlike the present study, these two earlier studies determined obesity using only BMI. Their findings might have been more important for the prevention of chronic diseases if they had also evaluated the extent of the association between dietary CQI and abdominal obesity, because abdominal obesity has a greater capacity to identify persons at increased risk of metabolic disorders than general obesity. ${ }^{35} 36$

There is evidence indicating that the individual components of CQI, such as high intake of fibre, greater intake of whole grains, higher intake of solid carbohydrates and consumption of diets low in GI, may help to reduce the chance of obesity and overweight. In a cross-sectional study, higher dietary GI was significantly associated with increased chance of obesity. ${ }^{37}$ Such positive associations between dietary GI and both general and central obesity in British adults were also reported. ${ }^{8}$ Similarly, in a randomised controlled clinical trial study (RCT) by Abete et al, participants in the low GI group lost a significantly greater amount of weight than their counterparts on high GI diets. ${ }^{38}$ In prospective studies, the consumption of 
Table 3 OR $(95 \% \mathrm{Cl})$ of obesity and overweight according to quintiles (q) of Carbohydrate Quality Index (CQI)

\begin{tabular}{|c|c|c|c|c|c|c|c|c|c|c|}
\hline \multirow{3}{*}{$\begin{array}{l}\text { Obesity and } \\
\text { overweight } \\
\text { measures }\end{array}$} & \multicolumn{9}{|l|}{ CQI } & \multirow[b]{3}{*}{$\mathbf{P}$ trend $\neq$} \\
\hline & \multirow{2}{*}{$\begin{array}{l}\text { Q1 } \\
\text { (53) } \\
\text { Ref* }^{*}\end{array}$} & \multicolumn{2}{|c|}{ Q2 (57) } & \multicolumn{2}{|c|}{ Q3 (42) } & \multicolumn{2}{|l|}{ Q4 (79) } & \multicolumn{2}{|c|}{ Q5 (46) } & \\
\hline & & OR & $95 \% \mathrm{Cl}$ & OR & $95 \% \mathrm{Cl}$ & OR & $95 \% \mathrm{Cl}$ & OR & $95 \% \mathrm{Cl}$ & \\
\hline \multicolumn{11}{|l|}{ BMI } \\
\hline Model 1 & 1.00 & 0.38 & 0.18 to 0.83 & 0.75 & 0.33 to 1.69 & 0.15 & 0.07 to 0.34 & 0.23 & 0.10 to 0.56 & \\
\hline $\mathrm{P}$ value & & 0.01 & & 0.5 & & $<0.001$ & & 0.001 & & $<0.001$ \\
\hline Model 2 & 1.00 & 0.42 & 0.18 to 0.97 & 1.01 & 0.41 to 2.47 & 0.15 & 0.06 to 0.36 & 0.25 & 0.10 to 0.65 & \\
\hline $\mathrm{P}$ value & & 0.04 & & 0.9 & & $<0.001$ & & 0.004 & & $<0.001$ \\
\hline \multicolumn{11}{|l|}{ WC } \\
\hline Model 1 & 1.00 & 0.41 & 0.19 to 0.90 & 0.74 & 0.33 to 1.66 & 0.23 & 0.11 to 0.49 & 0.22 & 0.09 to 0.54 & \\
\hline $\mathrm{P}$ value $\dagger$ & & 0.02 & & 0.5 & & $<0.001$ & & 0.001 & & $<0.001$ \\
\hline Model 2 & 1.00 & 0.46 & 0.19 to 1.07 & 1.02 & 0.41 to 2.52 & 0.23 & 0.10 to 0.52 & 0.22 & 0.08 to 0.58 & \\
\hline $\mathrm{P}$ value & & 0.07 & & 0.9 & & $<0.001$ & & 0.002 & & 0.001 \\
\hline \multicolumn{11}{|l|}{ WHtR } \\
\hline Model 1 & 1.00 & 0.44 & 0.21 to 0.95 & 0.66 & 0.29 to 1.49 & 0.22 & 0.11 to 0.47 & 0.26 & 0.11 to 0.60 & \\
\hline $\mathrm{P}$ valuet & & 0.03 & & 0.3 & & $<0.001$ & & 0.002 & & $<0.001$ \\
\hline Model 2 & 1.00 & 0.50 & 0.22 to 1.18 & 0.90 & 0.36 to 2.25 & 0.23 & 0.10 to 0.51 & 0.27 & 0.11 to 0.69 & \\
\hline $\mathrm{P}$ value & & 0.1 & & 0.8 & & $<0.001$ & & 0.006 & & 0.001 \\
\hline \multicolumn{11}{|l|}{ Col } \\
\hline Model 1 & 1.00 & 1.01 & 0.48 to 2.15 & 1.33 & 0.59 to 2.99 & 0.96 & 0.48 to 1.94 & 0.85 & 0.38 to 1.89 & \\
\hline $\mathrm{P}$ value & & 0.9 & & 0.4 & & 0.9 & & 0.7 & & 0.7 \\
\hline Model 2 & 1.00 & 1.15 & 0.52 to 2.54 & 1.60 & 0.68 to 3.76 & 0.99 & 0.47 to 2.10 & 0.88 & 0.38 to 2.02 & \\
\hline$P$ value $\dagger$ & & 0.7 & & 0.3 & & 0.9 & & 0.7 & & 0.8 \\
\hline
\end{tabular}

Model 1: unadjusted; model 2: adjusted for age, energy intake (kcal/day), both of respondent and husband's education, physical activity and ethnicity. Pł trend; tests of linear trend across increasing quintiles of CQI were calculated for the models assessing chance of overweight/ obesity as measured by body mass index, WC, WC to height ratio and Col. To analyse these linear trends, the median value of CQI was imputed for each quintile and the new variable was treated as a continuous variable. All tests statistics are considered significant for $p<0.05$. ${ }^{*} \mathrm{Q} 1$ considered as reference and other four quintiles compared with this quintile.

†Statistical significance level. General obesity and overweight by BMI: 25 and above $\left(\mathrm{kg} / \mathrm{m}^{2}\right)$; (yes/no), abdominal obesity measures: high WC $\geq 80 \mathrm{~cm}$; (yes/no), high Col $\geq 1.18$; (yes/no), WHtR $\geq 0.5$; (yes/no).

BMI, body mass index; Col, Conicity Index; WC, waist circumference; WHtR, waist-to-height ratio.

liquid carbohydrates was positively associated with weight gain, whereas the intake of solid carbohydrate food products was inversely related to higher weight gain. ${ }^{39-42}$ In a cross-sectional study by Lin et al, a significant inverse association was found between total fibre intake and WC in a Belgian population. ${ }^{43}$ Such inverse associations were also reported from a pooled analysis of three large crosssectional studies in a Finish population. ${ }^{44}$ Moreover, in a meta-analysis of 12 RCTs in overweight and obese adults, dietary fibre supplementation, compared with a placebo, reduced BMI, body weight and body fat. ${ }^{45}$ In two epidemiological studies by $\mathrm{O}^{\prime} \mathrm{Neil} e t a l^{46}$ and McKeown et $a l^{47}$ whole grain product consumption was inversely associated with BMI and WC.

The present study found slightly higher means for solid CHO-to-total $\mathrm{CHO}$ ratio and total fibre intake among participants classified under Q2 than those in Q3. This may explain the higher OR for general obesity in Q3 than in Q2. OR was also higher in Q5 than in Q4. What might have influenced these results is unclear; however, it may have been because the average dietary GI was higher in Q5 than in Q4.

The underlying mechanisms for the inverse relationship between dietary CQI and chance of obesity/ overweight as observed in the current study cannot be conclusively addressed. However, it seems that individual components of CQI may have played a role. With respect to the influence of low GI in obesity development, there is evidence that low GI diets increase satiety with a corresponding decrease in voluntary food intake, thus reducing total energy intake, which is beneficial for body weight maintenance and may prevent obesity. ${ }^{48-51}$ In contrast, the intake of a high GI diet causes increases in hunger and subsequently leads to the increased intake of food, thus potentially affecting energy balance and body composition. ${ }^{52}$ Dietary fibres, on the other hand, have the capacity to delay intestinal transit, improve insulin sensitivity, and help modulate glucose and lipid oxidation, 
which are beneficial to body weight regulation. ${ }^{53-55}$ Furthermore, they have the ability to prolong satiety, thereby reducing the chance of excessive dietary energy intake. ${ }^{565}$ The potential mechanisms that could explain the relation to whole-grain consumption and prevention of overweight and obesity are mainly their effect on satiety and their capacity to slow down starch digestion and absorption, which may lead to lower glucose and insulin responses. ${ }^{589}$ The consumption of dietary carbohydrate foods in their liquid or solid form may affect the chance of obesity by varying degrees. In general, liquid carbohydrates produce less satiety compared with solid carbohydrates, thus increasing the tendency of excessive energy intake, ${ }^{6061}$ a major risk for obesity. ${ }^{62} 63$ Moreover, liquid carbohydrate diets such as sugar-sweetened beverages are often high in $\mathrm{GI}^{18}{ }^{64}$; therefore, they have the potential to increase postprandial blood glucose levels and decrease insulin sensitivity while raising the risk of obesity and overweight. ${ }^{64}$

The present study has important strengths. To the best of the authors' knowledge, this study was the first to investigate carbohydrate quality in a broad fashion and its relationship with general and abdominal obesity in Africa. Necessary precautions were taken to enhance data quality during data collection and analysis. Despite these strengths, the study was not without some limitations. First, the sample size was relatively small. Second, due to the cross-sectional design of the study, the findings do not establish causality between CQI and obesity/ overweight; therefore, the results ought to be interpreted with caution. Third, this study employed 24 hours dietary recalls for dietary intake assessment; thus, the misreporting of food items cannot be ruled out completely due to memory-related issues. Additionally, there was the chance for the under-reporting of foods perceived to be unhealthy and over-reporting of food items perceived to be healthy. There was also the likelihood that overweight participants under-reported food intake. Fourth, despite the fact that the data were controlled for some potential confounders, the effects of eating behaviour, menopausal status, genetic variations and residual confounding cannot be discounted. Fifth, the study period was relatively short; therefore, we cannot discount the possibility of the effects of seasonal variations in food intake. With these potential errors, the ideal relationship between CQI and anthropometric measures could be distorted.

\section{CONCLUSION}

The present study demonstrated that there is an inverse association between dietary CQI and chance for both general and abdominal obesity in women. These relationships remained significant even after adjusting for potential confounding variables. The present findings provide important information, which may be useful for carbohydrate nutrition planning in obesity and overweight prevention and management in Ghana and beyond.

\section{Author affiliations}

${ }^{1}$ Department of Community Nutrition, School of Nutritional Sciences and Dietetics, International College, Tehran University of Medical Sciences, Tehran, Iran, Tehran,

Iran (the Islamic Republic of)

2Department of Community Nutrition, Tehran University of Medical Sciences, Tehran, Iran (the Islamic Republic of)

${ }^{3}$ Community Nutrition, University for Development Studies, Tamale, Ghana ${ }^{4}$ Epidemiology and Biostatistics, School of Public Health, Tehran University of Medical Sciences, Tehran, Iran, Islamic Republic of

${ }^{5}$ Community Nutrition, School of Nutritional Sciences and Dietetics, Tehran, Iran (the Islamic Republic of)

Acknowledgements We thank authorities of the International Campus of Tehran University of Medical Sciences and the department of Community Nutrition for their support during the design of this study. We also extend our profound gratitude to all study participants who made it possible for us to obtain data for this study.

Contributors SBS has made substantial contributions to conception and design and has been involved in drafting of the manuscript. GS has made substantial contributions to the design, revised the manuscript critically and given final approval of the version to be submitted. MS has made substantial contributions to conception and revised the manuscript. FS has made substantial contributions to conception and design. ARF has contributed greatly in offering advice on statistical design and analysis.

Funding This project was supported by the International Campus of Tehran University of Medical Sciences under grant number 9513475002.

Competing interests None declared.

Patient consent for publication Not required.

Ethics approval The study protocol was approved by the Ethics Committee of Tehran University of Medical Sciences, Tehran, Iran (IR.TUMS.VCR.REC.1397.4928) and the Ethics Review Committee of Tamale Teaching Hospital, Tamale, Ghana (TTHERC.19/06/18/02).

Provenance and peer review Not commissioned; externally peer reviewed.

Data availability statement Data are available on reasonable request.

Open access This is an open access article distributed in accordance with the Creative Commons Attribution Non Commercial (CC BY-NC 4.0) license, which permits others to distribute, remix, adapt, build upon this work non-commercially, and license their derivative works on different terms, provided the original work is properly cited, appropriate credit is given, any changes made indicated, and the use is non-commercial. See: http://creativecommons.org/licenses/by-nc/4.0/.

ORCID iD

Gity Sotoudeh http://orcid.org/0000-0001-6541-2581

\section{REFERENCES}

1 Kelly T, Yang W, Chen C-S, et al. Global burden of obesity in 2005 and projections to 2030. Int J Obes 2008;32:1431-7.

2 Stevens GA, Singh GM, Lu Y, et al. National, regional, and global trends in adult overweight and obesity prevalences. Popul Health Metr 2012;10:1.

3 Ofori-Asenso R, Agyeman AA, Laar A, et al. Overweight and obesity epidemic in Ghana-a systematic review and meta-analysis. BMC Public Health 2016;16.

4 Sartorius K, Sartorius B, Madiba TE, et al. Does high-carbohydrate intake lead to increased risk of obesity? A systematic review and meta-analysis. BMJ Open 2018;8:e018449.

5 Youssef MM, Mohsen MA, El-soud NHA, et al. Energy intake, diet composition among low social class overweight and obese Egyptian adolescents. J Am Sci 2010;6:160-8.

6 El-Asfahani AM, El-Asfahani AMA, Index G. Glycemic index and glycemic load: their relationship to adiposity in college students. $J$ Am Diet Assoc 2005;105:25.

7 Salari-Moghaddam A, Keshteli AH, Haghighatdoost F, et al. Dietary glycemic index and glycemic load in relation to general obesity and central adiposity among adults. Clin Nutr 2019;38:2936-42.

8 Murakami K, McCaffrey TA, Livingstone MBE. Associations of dietary glycaemic index and glycaemic load with food and nutrient intake and general and central obesity in British adults. Br J Nutr 2013;110:2047-57. 
9 Romaguera D, Ängquist L, Du H, et al. Dietary determinants of changes in waist circumference adjusted for body mass index - a proxy measure of visceral adiposity. PLoS One 2010;5:e11588.

10 Fuseini A-M, Rahimi MH, Mollahosseini $\mathrm{M}$, et al. The association between dietary glycemic index and glycemic load and a body shape and fat distribution among apparently healthy Iranian adults. $J$ Am Coll Nutr 2018;37:415-22.

11 Mogre V, Nyaba R, Aleyira S, et al. Demographic, dietary and physical activity predictors of general and abdominal obesity among university students: a cross-sectional study. Springerplus 2015;4:226.

12 Mogre V, Mwinlenaa PP, Oladele J, et al. Impact of physical activity levels and diet on central obesity among civil servants in Tamale Metropolis. J Med Biomed Sci 2012;1:1-9.

13 Zazpe I, Sánchez-Taínta A, Santiago S, et al. Association between dietary carbohydrate intake quality and micronutrient intake adequacy in a Mediterranean cohort: the sun (Seguimiento Universidad de Navarra) project. Br J Nutr 2014;111:2000-9.

14 Santiago S, Zazpe I, Bes-Rastrollo M, et al. Carbohydrate quality, weight change and incident obesity in a Mediterranean cohort: the sun project. Eur J Clin Nutr 2015;69:297-302.

15 Kim D-Y, Kim SH, Lim H. Association between dietary carbohydrate quality and the prevalence of obesity and hypertension. $J$ Hum Nutr Diet 2018;31:587-96.

16 Amugsi DA, Mittelmark MB, Oduro A. Association between maternal and child dietary diversity: an analysis of the Ghana demographic and health survey. PLoS One 2015;10:e0136748-12.

17 Rosner BBelmont C, ed. Fundamentals of biostatistics. 6th. USA: Brooks/Cole Publishing Co, 2006.

18 Atkinson FS, Foster-Powell K, Brand-Miller JC, Kaye R. International tables of glycemic index and glycemic load values: 2008. Diabetes Care 2008;31:2281-3.

19 The University of Sydney. Glycemic index research service (SUGiRS - Gi foods advanced search, 2018. Available: http://www. glycemicindex.com/foodSearch.php [Accessed 17 Oct 2018]

20 Prasad MPR, Rao BD, Kalpana K, et al. Glycaemic index and glycaemic load of sorghum products. J Sci Food Agric 2015;95:1626-30.

21 Eli-Cophie D, Agbenorhevi JK, Annan RA. Glycemic index of some local staples in Ghana. Food Sci Nutr 2017;5:131-8.

22 USDA. United States department of agriculture food composition databases show nutrients list, 2018. Available: https://ndb.nal.usda. gov/ndb/nutrients/index

23 Willett W. Issues in Analysis and Presentation of Dietary Data. In: Nutritional epidemiology. New York, NY: Oxford University Press, 1998: 321-46.

24 Culberson A, Kafai MR, Ganji V. Glycemic load is associated with $\mathrm{HDL}$ cholesterol but not with the other components and prevalence of metabolic syndrome in the third National health and nutrition examination survey, 1988-1994. Int Arch Med 2009;2:3-8.

25 Willett W, STAMPFER MJ. Total energy intake: implications for epidemiologic analyses. Am J Epidemiol 1986;124:17-27.

26 World Health Organization. Obesity: preventing and managing the global epidemic. Report of a who consultation. World Health Organ Tech Rep Ser. Who 2000;894:1-253.

27 WHO. Waist circumference and waist-hip ratioReport of a who expert consultation, Geneva, 8-11 December 2008; 2008.

28 Alberti KGMM, Eckel RH, Grundy SM, et al. Harmonizing the metabolic syndrome. Circulation 2009;120:1640-5.

29 Valdez R. A simple model-based index of abdominal adiposity. J Clin Epidemiol 1991;44:955-6.

30 Pitanga FJG, Lessa I. [Anthropometric indexes of obesity as an instrument of screening for high coronary risk in adults in the city of Salvador--Bahia]. Arq Bras Cardiol 2005;85:26-31.

31 Ashwell M, Hsieh SD. Six reasons why the waist-to-height ratio is a rapid and effective global indicator for health risks of obesity and how its use could simplify the International public health message on obesity. Int J Food Sci Nutr 2005;56:303-7.

32 International Physical Activity Questionniare Group. International physical activity questionnaire short last 7 days self-administered format for use with young and middle aged adults. Res $Q$ Exerc Sport 2002

33 Steyn NP, Mchiza ZJ. Obesity and the nutrition transition in subSaharan Africa. Ann N Y Acad Sci 2014;1311:88-101.

34 Basu S, McKee M, Galea G, et al. Relationship of soft drink consumption to global overweight, obesity, and diabetes: a cross-national analysis of 75 countries. Am J Public Health 2013;103:2071-7.

35 Després J-P, Lemieux I, Bergeron J, et al. Abdominal obesity and the metabolic syndrome: contribution to global cardiometabolic risk. Arterioscler Thromb Vasc Biol 2008;28:1039-49.
36 von Eyben FE, Mouritsen E, Holm J, et al. Intra-Abdominal obesity and metabolic risk factors: a study of young adults. Int $J$ Obes 2003;27:941-9.

37 Youn S, Woo HD, Cho YA, et al. Association between dietary carbohydrate, glycemic index, glycemic load, and the prevalence of obesity in Korean men and women. Nutr Res 2012;32:153-9.

38 Abete I, Parra D, Martinez JA. Energy-restricted diets based on a distinct food selection affecting the glycemic index induce different weight loss and oxidative response. Clin Nutr 2008;27:545-51

39 Mozaffarian D, Hao T, Rimm EB, et al. Changes in diet and lifestyle and long-term weight gain in women and men. N Engl J Med 2011;364:2392-404.

40 Fogelholm M, Anderssen S, Gunnarsdottir I, et al. Dietary macronutrients and food consumption as determinants of long-term weight change in adult populations: a systematic literature review. Food Nutr Res 2012;56.

41 Hutfless S, Gudzune KA, Maruthur N, et al. Strategies to prevent weight gain in adults. Am J Prev Med 2013;45:e41-51.

$42 \mathrm{Du} \mathrm{H}$, van der A DL, Boshuizen $\mathrm{HC}$, et al. Dietary fiber and subsequent changes in body weight and waist circumference in European men and women. Am J Clin Nutr 2010;91:329-36.

43 Lin Y, Huybrechts I, Vandevijvere S, et al. Fibre intake among the Belgian population by sex-age and sex-education groups and its association with BMI and waist circumference. $\mathrm{Br} J$ Nutr 2011;105:1692-703

44 Kaartinen NE, Knekt P, Kanerva N, et al. Dietary carbohydrate quantity and quality in relation to obesity: a pooled analysis of three Finnish population-based studies. Scand J Public Health 2016;44:385-93.

45 Thompson SV, Hannon BA, An R, et al. Effects of isolated soluble fiber supplementation on body weight, glycemia, and insulinemia in adults with overweight and obesity: a systematic review and meta-analysis of randomized controlled trials. Am J Clin Nutr 2017:106:1514-28.

46 O'Neil CE, Zanovec M, Cho SS, et al. Whole grain and fiber consumption are associated with lower body weight measures in US adults: National health and nutrition examination survey 1999-2004. Nutr Res 2010;30:815-22.

47 McKeown NM, Yoshida M, Shea MK, et al. Whole-Grain intake and cereal fiber are associated with lower abdominal adiposity in older adults. J Nutr 2009;139:1950-5.

48 Arumugam V, Lee J-S, Nowak JK, et al. A high-glycemic meal pattern elicited increased subjective appetite sensations in overweight and obese women. Appetite 2008;50:215-22.

49 Ludwig DS. The glycemic index: physiological mechanisms relating to obesity, diabetes, and cardiovascular disease. JAMA 2002;287:2414-23.

50 Esfahani A, Wong JMW, Mirrahimi A, et al. The glycemic index: physiological significance. J Am Coll Nutr 2009;28:439S-45.

51 Burton-Freeman BM, Keim NL. Glycemic index, cholecystokinin, satiety and disinhibition: is there an unappreciated paradox for overweight women? Int J Obes 2008;32:1647-54.

52 Goss AM, Goree LL, Ellis AC, et al. Effects of diet macronutrient composition on body composition and fat distribution during weight maintenance and weight loss. Obesity : 2013;21:1139-42.

53 Sleeth ML, Thompson EL, Ford HE, et al. Free fatty acid receptor 2 and nutrient sensing: a proposed role for fibre, fermentable carbohydrates and short-chain fatty acids in appetite regulation. Nutr Res Rev 2010;23:135-45.

54 Kasubuchi M, Hasegawa S, Hiramatsu T, et al. Dietary gut microbial metabolites, short-chain fatty acids, and host metabolic regulation. Nutrients 2015;7:2839-49.

55 Giacco R, Della Pepa G, Luongo D, et al. Whole grain intake in relation to body weight: from epidemiological evidence to clinical trials. Nutr Metab Cardiovasc Dis 2011;21:901-8.

56 Slavin J, Green H. Dietary fibre and satiety. Nutr Bulletin 2007;32:32-42

57 Kristensen M, Jensen MG, Riboldi G, et al. Wholegrain vs. refined wheat bread and pasta. Effect on postprandial glycemia, appetite, and subsequent $A D$ libitum energy intake in young healthy adults. Appetite 2010;54:163-9.

58 Cho SS, Qi L, Fahey GC, et al. Consumption of cereal fiber, mixtures of whole grains and bran, and whole grains and risk reduction in type 2 diabetes, obesity, and cardiovascular disease. Am J Clin Nutr 2013;98:594-619.

59 Wanders AJ, van den Borne JJGC, de Graaf C, et al. Effects of dietary fibre on subjective appetite, energy intake and body weight: a systematic review of randomized controlled trials. Obes Rev 2011;12:no-39. 
60 Moran TH. Fructose and satiety. J Nutr 2009;139:1253S-6.

61 Bray GA. Soft drink consumption and obesity: it is all about fructose. Curr Opin Lipidol 2010;21:51-7.

62 Vernarelli JA, Mitchell DC, Rolls BJ, et al. Dietary energy density and obesity: how consumption patterns differ by body weight status. Eur J Nutr 2018;57:351-61.
63 Rouhani MH, Haghighatdoost F, Surkan PJ, et al. Associations between dietary energy density and obesity: a systematic review and meta-analysis of observational studies. Nutrition 2016;32:1037-47.

64 Harrington S. The role of sugar-sweetened beverage consumption in adolescent obesity: a review of the literature. J Sch Nurs 2008;24:3-12. 